\title{
Characterizing the zonally asymmetric component of the SH circulation
}

\author{
William R. Hobbs $•$ Marilyn N. Raphael
}

Received: 5 February 2009/ Accepted: 9 September 2009/Published online: 17 September 2009

(c) The Author(s) 2009. This article is published with open access at Springerlink.com

\begin{abstract}
Much research concerning the Southern Hemisphere (SH) zonally asymmetric circulation has focused on the Pacific-South American mode (PSA) or the major zonal waves. However, these large-scale decompositions may mask important local variability. In this paper the monthto-month variability explained by the zonal waves 1 and 3 is examined, and an alternative representation of the SH circulation is presented based on two quasi-stationary anticyclones in the sub-Antarctic western hemisphere. These anticyclones are related to the zonal waves, but features of their variability are masked by the zonal wave decomposition; in particular, the anticyclones' strengths are not positively covariant. They are also compared with the leading Principal Components of the $\mathrm{SH}$ atmosphere. We show that they capture variance independent of the Southern Annular Mode. Additionally, they explain a generally greater fraction of the variability than the PSA, and in a manner that also includes information regarding spatial variability. These results have implications for analysis of the atmosphericforcing of western Antarctic climate.
\end{abstract}

Keywords Climate variability - Southern Hemisphere . Zonal waves · Pacific-South American Mode .

Southern Annular Mode

\section{Introduction}

Since recent Antarctic climate change is spatially heterogeneous and has potentially global significance, a clear

W. R. Hobbs $(\varangle) \cdot$ M. N. Raphael

Department of Geography, University of California Los Angeles, 1255 Bunche Hall, Los Angeles, CA 90095, USA

e-mail:whobbs@ucla.edu understanding of the high latitude Southern Hemisphere (SH) circulation at regional scales is critically important. Over the late twentieth century, the west Antarctic region has shown one of the strongest warming trends globally; but by contrast there has been little significant trend elsewhere in Antarctica (Marshall et al. 2002; Vaughn et al. 2003; Turner et al. 2006; Monaghan et al. 2008; Steig et al. 2009). Over the same period there have been observed trends in west Antarctic sea ice; since 1979 there has been a significant increase in sea ice extent in the Ross and Amundsen Seas, but a decrease in the Bellingshausen and Weddell Seas of approximately $4-10 \% /$ decade (Liu et al. 2004). These changes in sea ice and surface temperature have major implications for the stability of the west Antarctic ice sheet, and thus for eustatic sea level (Thomas et al. 2004).

A possible driver for these observed changes is thought to be the quasi-zonally symmetric Southern Annular Mode (SAM), the dominant mode of atmospheric variability in the Southern Hemisphere high latitude (Thompson and Wallace 2000; Thompson et al. 2000). There is a robust positive correlation between Antarctic Peninsula (AP) temperature and the strength of the SAM (Thompson and Solomon 2002; Kwok and Comiso 2002; Marshall et al. 2006), and a significant strengthening of the SAM has been reported over the period of observed AP warming (Gong and Wang 1999; Thompson et al. 2000; Marshall 2003). However, important aspects of the SH climate cannot be explained by the SAM alone. Recent results indicate that recent warming has not been restricted to the AP as previously thought, but has been significant across the entire west Antarctica ice sheet. Also, the seasonal pattern of warming is not consistent with a response to SAM trends (Steig et al. 2009). Liu et al. (2004) showed that relatively little of the recent trends in west Antarctic sea ice can be 
related to the SAM, whilst Lefebvre and Goosse (2008) showed that atmospheric influence on total winter sea ice variability does not project onto any of the currently recognized SH climate modes.

The zonally asymmetric component of the SH atmosphere is commonly analyzed with regard to either the zonal harmonic waves, or the Pacific-South American mode (PSA). The PSA describes a wavetrain running from the equatorial Pacific to the southern tip of South America, before refracting back northwards over the Atlantic (Mo and Ghil 1987). Since it is related to tropical Pacific convection, it is thought to be partly responsible for the teleconnection of El Nino-Southern Oscillation (ENSO) variability to the SH high latitudes (e.g. Karoly 1989; Mo and Higgins 1997; Kiladis and Mo 1998). The PSA mode generally appears in the both the second and third Principal Components (PCs) of the SH pressure field rather than as a single decomposition; the second and third PCs were dubbed the PSA1 and PSA2 patterns by Mo and Higgins (1997). This spread across two components may be partly due to the time scales they represent; Mo and Paegle (2001) argue that PSA1 represents the response to interannual ENSO variability, and PSA2 is associated with the quasibiennial ENSO component.

PC analysis is limited as an analysis tool by the timeindependent patterns of variability returned. Temporal variability is expressed with respect to the relative importance of the spatial eigenvector at each time step through their amplitude time series, the spatial pattern of each mode is inherently unchanging. Recent research indicates that spatial changes in the atmospheric circulation are at least as important as changes in the strength of recognized modes (Bertler et al. 2004; Raphael 2007). Decomposition into zonal waves by the Fourier transform gives a little more information in this regard, since the decomposition returns information regarding the phase (i.e. the longitude of the first wave peak) as well as the amplitude of each harmonic, but with the disadvantage that the spatial pattern returned is constrained to well-behaved sinusoidal waveforms, which may or may not be the best representation of the atmospheric state. In the SH the dominant waves are zonal waves 1 (ZW1) and 3 (ZW3). In the mean, ZW1 and ZW3 between them explain over $90 \%$ of the SH pressure field's mean spatial distribution (van Loon and Jenne 1972; Trenberth 1980). It has been suggested that the ZW3 crests are generally not covariant in their activity (Trenberth and Mo 1985), which raises the question of whether the ZW3 pattern represents a single mode of variability, or whether the wave peaks are in fact independent quasi-stationary features of the SH circulation. Hence, the major motivation for this research was to ascertain how well the Fourier transform zonal waves actually capture the SH mid-troposphere's variability at monthly and inter-annual time scales.
As an initial step, the monthly mean zonal anomaly of the geopotential height field at each month for 1979-2007 was compared with the same month's ZW1 and ZW3 patterns. The results for a typical month are shown in Fig. 1. There is a generally higher pressure in the high latitude Pacific basin compared to the Indian basin, which can be interpreted as the persistently strong ZW1 (Fig. 1c). The Pacific basin shows two obvious anticyclones, whose spatial location suggests a relation to ZW3 (Fig. 1d). These anticyclones prove to be quasi-stationary features of the monthly mean pressure field. The eastern anticyclone is colocated with the variance maximum (Fig. 1a, e) and close to the west Antarctic region, and the western anticyclone occurs south of New Zealand, an important region for poleward storm tracks (Quintanar and Mechoso 1995). The superposed ZW1/ZW3 pattern reproduces the zonal anomaly well (Fig. 1b), so that at a first pass it seems that the variability of the subpolar anticyclones is well-captured by ZW3. (The $500 \mathrm{hPa}$ geopotential height zonal anomaly for each month analyzed may be viewed using the supplementary animation).

A feature of the SH circulation that is common to both the PSA and zonal waves discussed above (and indeed to the SAM during some seasons) is that they all show strong, zonally anomalous centers of action in the Pacific sector of the sub-Antarctic region. By considering the variability of quasi-stationary zonal anomalies directly and individually rather than through large-scale decompositions, it is hoped that fresh insight will be gained that help to explain the dynamics of the important climate modes that are identified by PC and Fourier analysis. This paper presents a statistical analysis characterizing the large-scale influence of the subAntarctic quasi-stationary anticyclones on the SH atmosphere. Section 2 outlines the data and the method of analysis; in Sect. 3 the variability of the subpolar Pacific anticyclones is discussed, with reference to their zonal wave representation; in Sect. 4 the anticyclones are compared with the leading PCs of climate variability; the results are summarized in Sect. 5.

\section{Method}

The primary dataset used in this analysis is the NCEP/ NCAR reanalysis data (NRA) $500 \mathrm{hPa}$ geopotential height (Kalnay et al. 1996). Geopotential height at the $500 \mathrm{hPa}$ level (500Z) includes many of the patterns of variability that influence SH surface climate and is reasonably independent of the reanalysis model surface-process parameterizations (Kalnay et al. 1996). Although the aim of reanalysis is a temporally homogeneous dataset, the inclusion of satellite data from 1979 onwards is thought to have led to spurious trends in the SH high latitudes (e.g. 

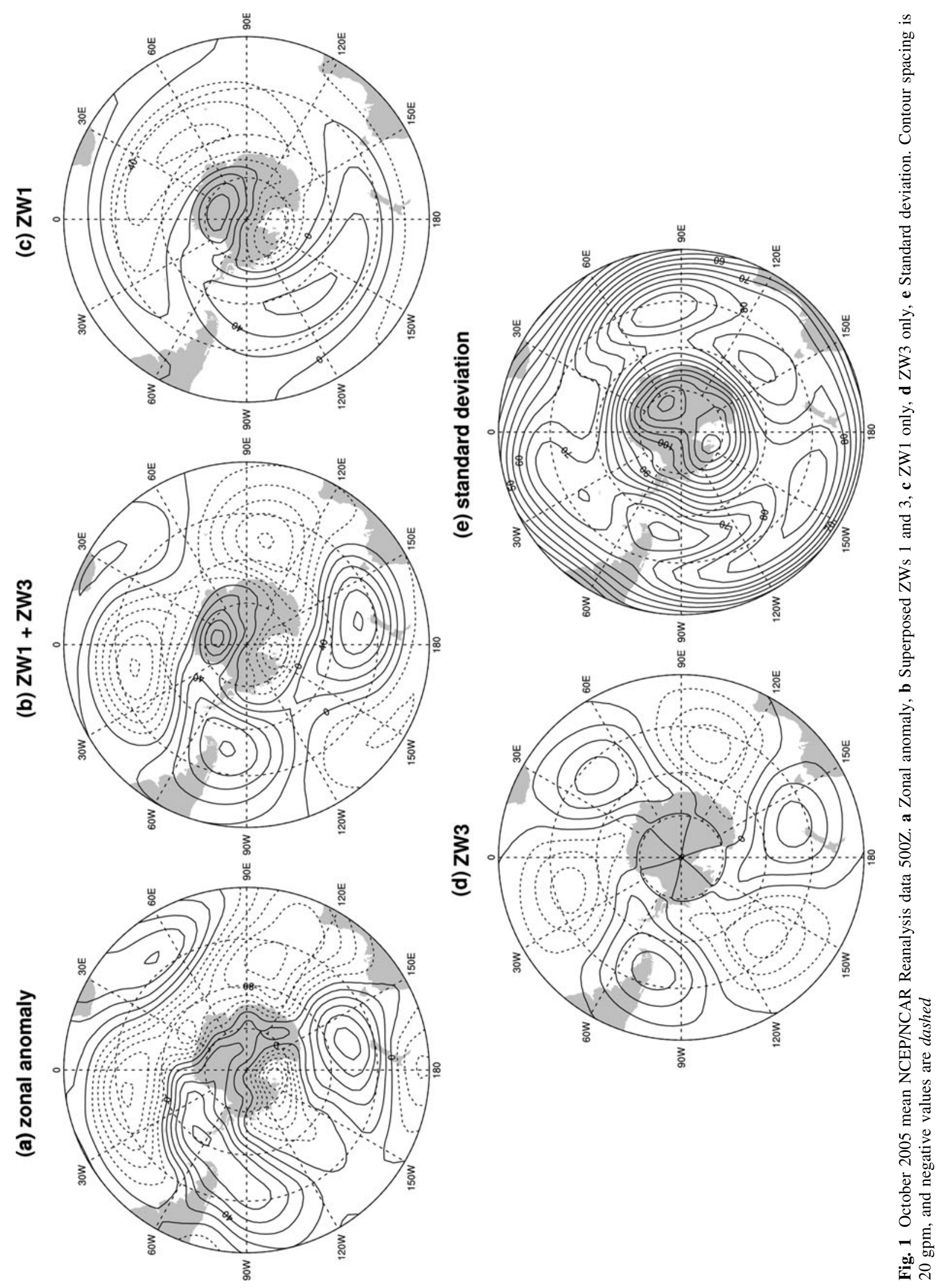
Marshall 2003). To eliminate these spurious trends this study is limited to post-satellite period of January 1979December 2007. Additionally, remaining linear trends have been removed from the data prior to analysis unless otherwise stated. Marshall (2003) and Fogt and Bromwich (2006) suggest that the ECMWF 40-year reanalysis (ERA40) is a better representation of the high latitude $\mathrm{SH}$ climate, but ERA40 is only available up to 2001 (Uppala et al. 2005). To give the longest possible period of analysis with reliable data NRA was chosen as the primary dataset, but the results presented here have been compared with those derived from the ERA40 data, and are found to be insensitive to the choice of reanalysis.

Time series were generated representing each anticyclone's strength and longitude (HGTE and LONE, respectively, for the east anticyclone; HGTW and LONW for the west anticyclone). For each month, the zonal-mean was removed from the $500 \mathrm{Z}$ and the zonal anomaly field was spatially smoothed by two-dimensional nine-point local smoothing to remove any minor grid point maxima. The local maxima of the resultant field were found within the spatial domain $130^{\circ} \mathrm{E}-360^{\circ} \mathrm{E}, 40^{\circ} \mathrm{S}-75^{\circ} \mathrm{S}$. Visual inspection of the geopotential height field for each month confirmed that the chosen spatial domain captured the variability of the monthly mean anticyclones. The strength and longitude of the easternmost and westernmost anticyclones were recorded as time series.

In approximately $80 \%$ of the 348 months analyzed, two clear high-pressure anomalies emerged, as shown in Fig. 1a. Where this was not the case, visual inspection revealed that for approximately $10 \%$ of months analyzed the zonal-anomaly field showed a monopole pattern very similar to that of $\mathrm{ZW} 1$, and for the remaining $10 \%$ the magnitude of the zonal anomalies was found to be weak and dissimilar to the double-anticyclone pattern. To assess the influence of these monopole and poor-fit months, the time series derived from the NRA and ERA40 were compared, for different cases of quality control. These quality control cases were: no data removed from the time series; months flagged as showing a monopole pattern removed; months flagged as showing a poor fit to the double-anticyclone pattern; and all flagged months (i.e. monopole and 'poor fits') removed. The comparison was made with the assumption that the most robust representation of the anticyclones' variability would be the quality control case giving the best agreement between the time series derived from the NRA and ERA40 reanalyses. Agreement was assessed on the basis that the time series from the two reanalyses should show the same changes over time (i.e. they should be strongly positively correlated), and the magnitude of change between the two reanalyses should be the same (i.e. the linear regression coefficient between them should be as close as possible to 1 , since a departure from 1 would suggest that the variability of the anticyclone is much higher in one of the reanalyses than in the other). The comparison was performed for the monthly anomaly and 3-month seasonal means of the time series. The comparison indicated that the representation of the anticyclones' strength and longitude in the NRA and ERA40 datasets had the best agreement when both the monopole and poor-fit months are excluded. Unlike the months flagged as 'monopole', the poor-fit months were identified by eye rather than by an objective algorithm. Hence, to maintain the best compromise between a repeatable analysis and agreement between the anticyclone variability represented by the reanalysis datasets, only the monopole months were removed prior to analysis.

ZW1 variability was characterized by the subpolar amplitude and phase time series of Hobbs and Raphael (2007). These time series were generated in a similar fashion to those of the subpolar Pacific anticyclones. The ZW1 and ZW3 fields was calculated by applying the Fourier transform along the longitude coordinate of the $500 \mathrm{hPa}$ geopotential height, and the amplitude and phase were retrieved for each month. ZW3 amplitude and phase time series were derived from the $500 \mathrm{Z}$ field in exactly the same manner. The range of spatial variability causes the first and third ZW3 peaks to pass across the Greenwich Meridian (i.e. $0^{\circ} \mathrm{E}$ ). In order to avoid confusion by having a non-monotonic range of longitudinal coordinates the second peak was used to characterize the ZW3 phase variability, lying typically around $200^{\circ} \mathrm{E}$. This is different to the Raphael (2004) ZW3 index based on the normalized MSLP at three key SH locations, which because of its inability to separate the effects of strength and location was not used in this analysis. Additionally, initial results showed that the latitude to derive the Raphael (2004) ZW3 index $\left(49^{\circ} \mathrm{S}\right)$ is north of the main region of interest.

In this study the first $\mathrm{PC}$ of the $500 \mathrm{hPa}$ geopotential height was used to characterize SAM variability. (Note that throughout this paper PC refers specifically to the amplitude time series, and not the spatial eigenvector of each principal component). Although other SAM indices have been previously proposed based on $850 \mathrm{hPa}$ and sea-level pressure (Thompson and Wallace 2000; Gong and Wang 1999; Marshall 2003), $500 \mathrm{hPa}$ was chosen to maintain consistency with the anticyclone time series. Since the SAM is equivalent-barotropic the difference in heights should not influence the results.

As discussed in the Introduction, the PSA is shared amongst the second and third PCs of the SH geopotential height field (e.g. Mo and Higgins 1997). Yuan and Li (2008) suggest an index that is analogous to the PacificNorth America mode index, defined as PSA $=(\mathrm{H} 1+$ $\mathrm{H} 2-\mathrm{H} 3) / 3$, where $\mathrm{H} 1, \mathrm{H} 2, \mathrm{H} 3$ are the $500 \mathrm{Z}$ anomalies at three key locations $\left(\mathrm{H} 1=45^{\circ} \mathrm{W} 50^{\circ} \mathrm{S}, \mathrm{H} 2=170^{\circ} \mathrm{W} 45^{\circ} \mathrm{S}\right.$, 
and $\left.\mathrm{H} 3=120^{\circ} \mathrm{W} 67.5^{\circ} \mathrm{S}\right)$. A very high correlation was found between the SAM index and the Yuan and Li PSA index $(r=-0.93)$, indicating that the index is influenced by SAM as well as PSA variability. This likely due to the latitude difference between the sites $\mathrm{H} 1$ and $\mathrm{H} 2$ (mid-latitude) and H3 (high latitudes), and so captures the meridional pressure difference that characterizes the SAM. For comparison of the two modes with the subpolar anticyclones a clear separation between the SAM and PSA was desired, and so the second and third PCs were used to describe PSA variability rather than the Yuan and Li index.

Cross-correlations were deemed to be statistically significant if they met or exceeded the 0.05 level. After removal of the annual cycle, the HGTW, LONE and LONW time series are approximately white noise, while the HGTE time series is well-described by a first-order Markov [i.e. AR(1)] process. For correlations of monthly mean data, an equivalent sample-size was used to estimate statistical significance to account for serial autocorrelation (Zwiers and von Storch 1995). For correlations of seasonal and annual means, after removal of flagged data there were relatively few years for each season (approximately 14, depending on season), and a parametric significance estimation would be unreliable. Instead, correlation significance was estimated using a resampling approach, whereby $10^{5}$ random time series of the same length and standard deviation as the seasonal time series were correlated with each other. The random cross-correlations were Gaussian in distribution and correlations of $r=0.4$ or higher were found to be significant at the 0.05 level. This estimation was robust for the range of sample size and standard deviations of the four time series.

\section{Results}

\subsection{Trends and seasonality}

The monthly climatologies of each anticyclone time series are shown in Fig. 2. A striking feature is the weak annual cycle of the west anticyclone's strength compared to that of the east anticyclone (Fig. 2a, c). Both anticyclones reach their maximum in austral winter. The east anticyclone longitude (LONE) shows a six-month cycle with peaks in early spring and late summer (Fig. 2b), approximately in phase with the semi-annual oscillation (van Loon 1967). The semi-annual oscillation has centers of action in the subpolar Pacific region that are in the approximate locations of the east and west anticyclones, so it is curious that a 6-month cycle is not evident in any of the time series other than LONE. The 12-month cycles of the west and east peak longitude are approximately in phase, such that both reach their western extreme in the same season. On the basis of choosing 3-month means with approximately stationary time series (i.e. months with similar variance), where analysis by seasons was required the selected

\section{(a) HGTE}

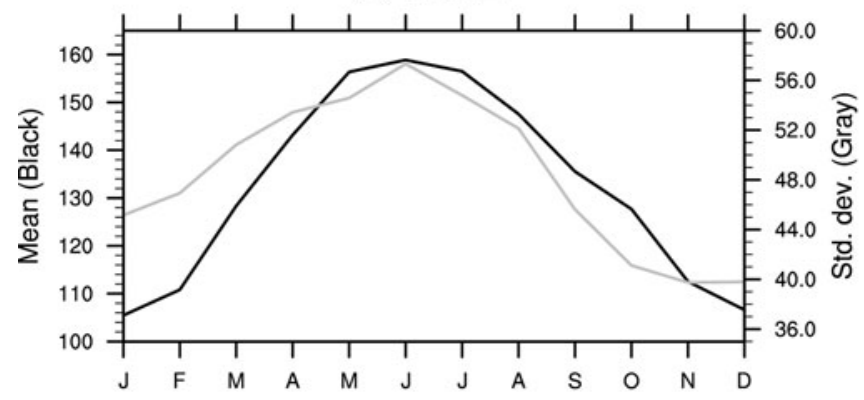

(c) AMPW

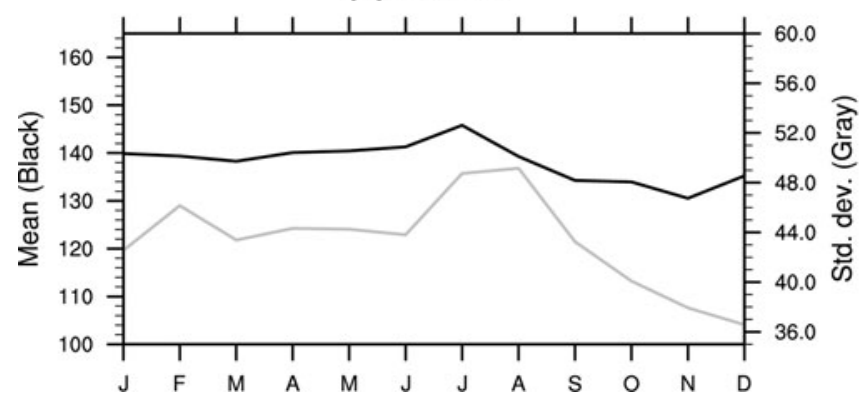

(b) LONE

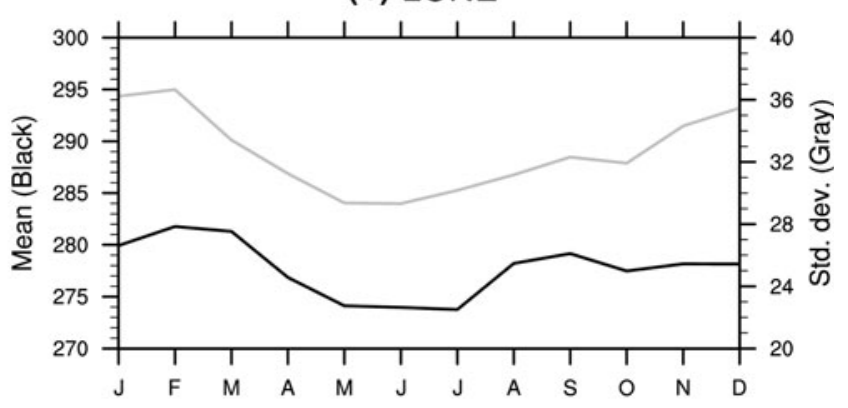

(d) LONW

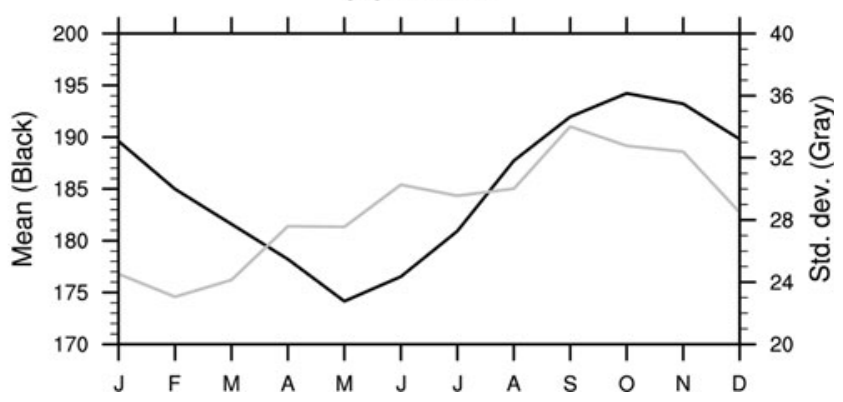

Fig. 2 Climatological mean (black) and standard deviation (gray) of 1979-2007. a East anticyclone height (HGTE), b East anticyclone longitude (LONE), c West anticyclone height (HGTW), and d West anticyclone longitude (LONW), smoothed by four-month moving average 
subpolar anticyclone seasons were MJJ (early winter), ASO (late winter), NDJ (early summer) and FMA (late summer).

To reduce the possibility of spurious trends in the reanalysis data, trends were calculated for 1980-2001 (the period of coverage for both datasets) and were considered robust only where they were statistically significant for both the NRA and ERA40 data. There were no significant trends in the annual means of any of the time series, but the HGTW time series had a significant negative trend for March [-4.4 (NRA), -4.1 (ERA40) gpm/year], indicating a weakening of the fall west anticyclone. This can be partly associated with the reduction in circumpolar pressure that is a component of the strengthened SAM. The LONW time series has a statistically significant negative trend during September (-1.7 (NRA), -1.4 (ERA40) ${ }^{\circ}$ E/year), suggesting a westward shift for the month when the west anticyclone is at its climatological easternmost extent (Fig. 2d), meaning a slight reduction in the range of the annual east-west shift of the west anticyclone.

\subsection{Interaction between anticyclone strength and location}

The relationships amongst the four anticyclone time series were explored by lagged cross-correlation. Correlations were performed for lags of up to 48 months, but only zerolag correlations were found to be statistically significant; these zero-lagged cross correlations for each 3-month seasonal mean are shown in Fig. 3. There is a significant negative correlation between HGTE and LONE (dashed purple), indicating that the east anticyclone is stronger when in its western phase (i.e. over the Amundsen/Bellingshausen Sea). There are significant correlations between the two anticyclones, the most consistent being between LONE and LONW (blue) indicating that the two anticyclones tend towards similar east-west phases,

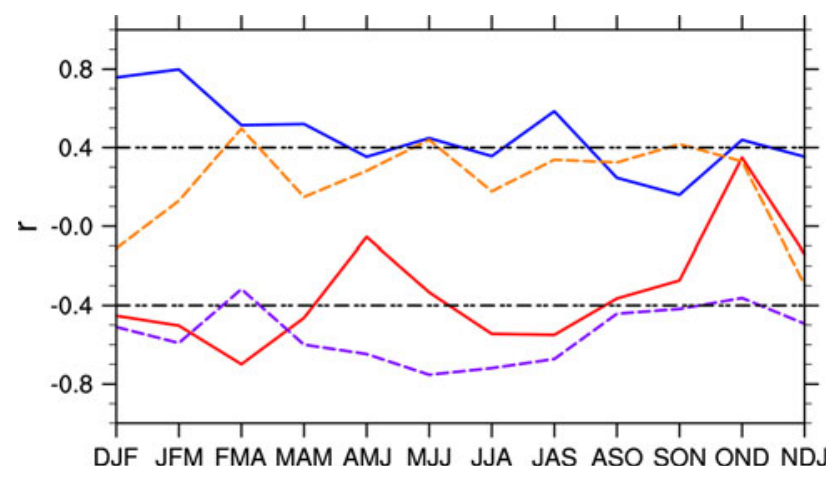

Fig. 3 Correlations amongst the anticyclones strength and location $(y$-axis), for each the 3-month seasonal mean ( $x$-axis), for HGTE, HGTW (red); LONE, LONW (blue); HGTE, LONE (dashed purple); HGTW, LONW (dashed orange). Horizontal dashed lines indicate correlations significant at the 0.05 level consistent with their in-phase 12-month cycles (Fig. 2b, d). HGTE and HGTW are negatively correlated through much of the year (Fig. 3, red line). This is consistent with Trenberth and Mo (1985), who showed that blocking in the approximate locations of the quasi-stationary anticyclones is rarely simultaneous.

These interactions clearly warrant further investigation that is beyond the scope of this paper. It is noted here that their covariances have implications for statistical analysis, as discussed in Sect. 3.3. This also has implications for the validity of the ZW3 pattern as represented by the Fourier transform. The in-phase east-west shift of the two anticyclones clearly supports their convenient representation by the ZW3 mode. However, by implication the ZW3 pattern represents the strength of the anticyclones as having amplitudes that vary in-phase, whereas this is clearly not consistent with the negative covariance in their strengths. A further drawback of the ZW3 pattern its representation of a third high-pressure anomaly over the south-west Indian Ocean (Fig. 1d). It is seen in Fig. 1a that for the sample month shown, there is a high-pressure anomaly over the Indian Ocean, but further north than in for the ZW3. Analysis of each month's zonal anomaly (see supplementary animation) confirmed that this is a common pattern, and that the Indian Ocean ZW3 lobe is largely spurious at sub-Antarctic latitudes.

\subsection{The subpolar anticyclones and SH climate variability}

To investigate the influence of the subpolar anticyclones on the $\mathrm{SH}$ circulation, the monthly mean $500 \mathrm{Z}$ field was correlated with the anticyclone time series (Fig. 4). The signals of anticyclone strength show some PSA-like negative correlations at lower latitudes (Fig. 4a, c). Correlations with the anticyclone longitudes are more zonally distributed; both anticyclone longitudes have a positive/negative dipole correlation either side of their mean locations, consistent east-west shifts of the high-pressure anomalies. Additionally, for both anticyclones the immediate dipole correlations form part of a wavenumber-3 pattern, which is somewhat stronger for the west anticyclone (Fig. 4d). They clearly share regions of covariance in the mid-Pacific sector, partly explaining the correlation between LONE and LONW.

The clear wavenumber-3 patterns in the correlations with $500 \mathrm{Z}$ indicate a link with the zonal waves. This potential relationship was further explored by cross-correlation (Fig. 5). The ZW1 amplitude is uncorrelated with the west anticyclone strength, but correlated with the east anticyclone strength during much of the year (Fig. 5a). A time series constructed from the highest strength at each month of the two anticyclones is significantly correlated 
(a) HGTE

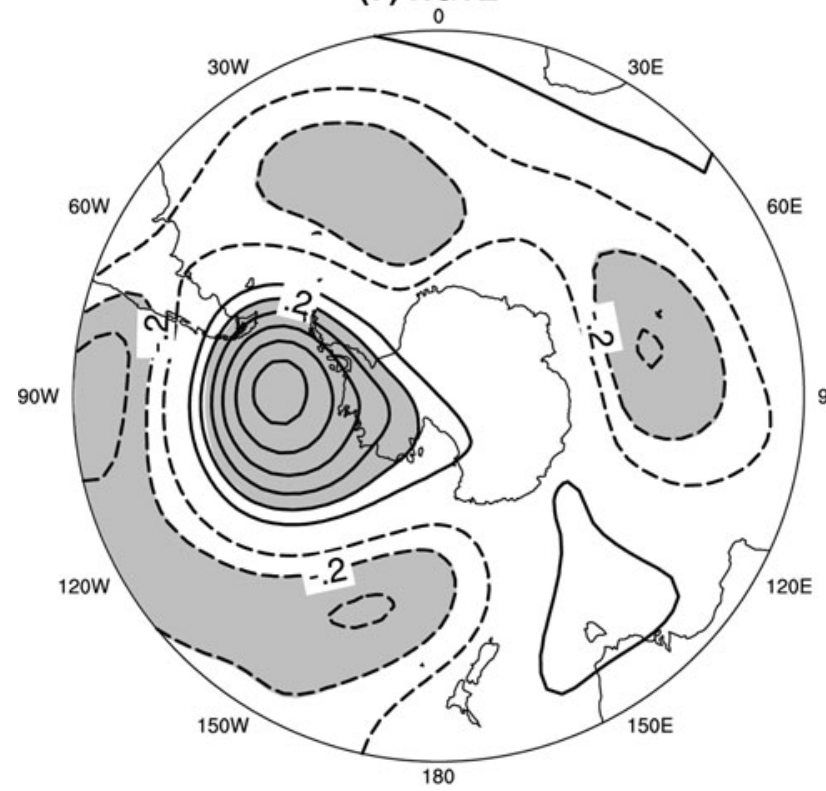

(c) HGTW

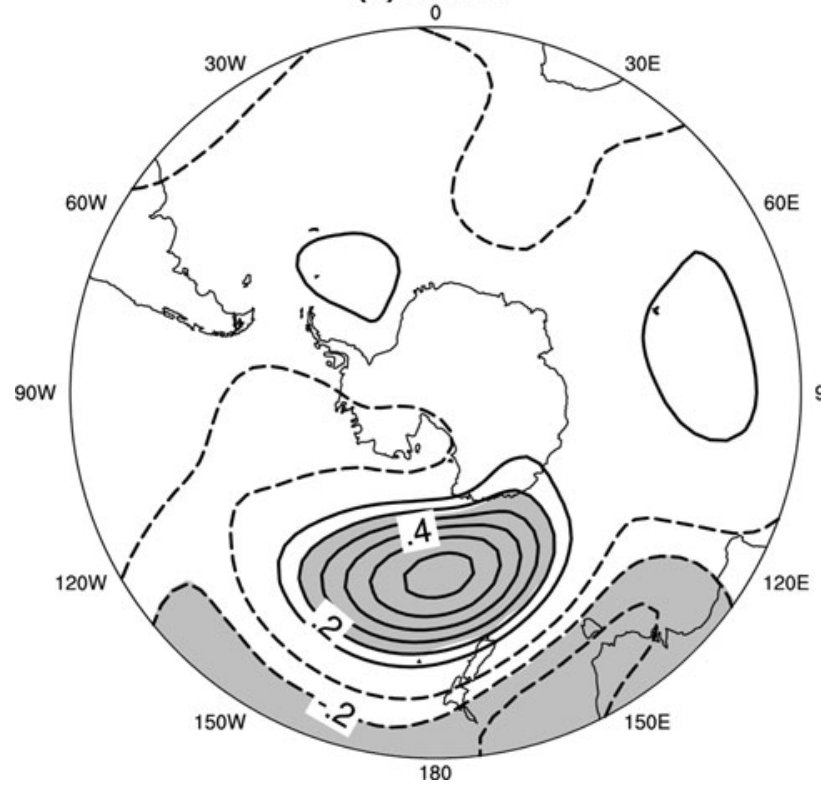

Fig. 4 Zero-lag cross-correlation between $500 \mathrm{Z}$ climatological anomaly and subpolar block anomalies for a HGTE, b LONE, c HGTW, d LONW. Contour intervals are 0.1 , with no zero-contour.

with ZW1 amplitude annual mean $(r=0.77)$ and throughout the year (Fig. 5a, magenta line). ZW1 phase does not seem to be correlated with the longitude of either of the anticyclones (Fig. 5b). The link between anticyclone strength and ZW1 phase and amplitude suggests that the SH ZW1 generated by the Fourier Transform can be interpreted as an expression of the higher pressure in the subpolar western compared to the eastern hemisphere, due to the presence of both the anticyclones in the western hemisphere. (b) LONE

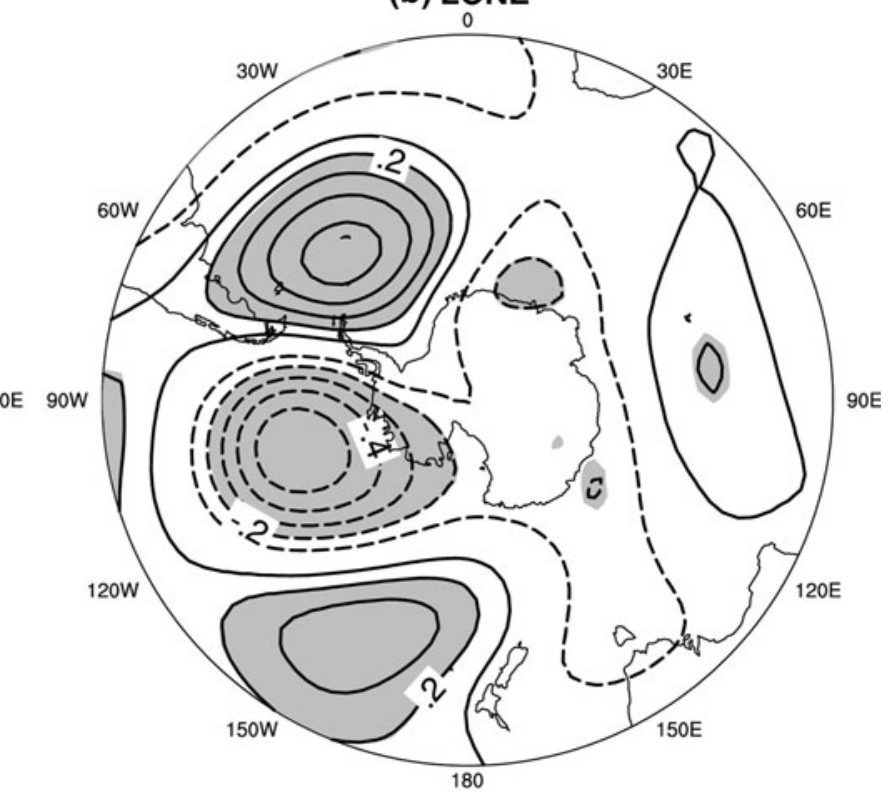

(d) LONW

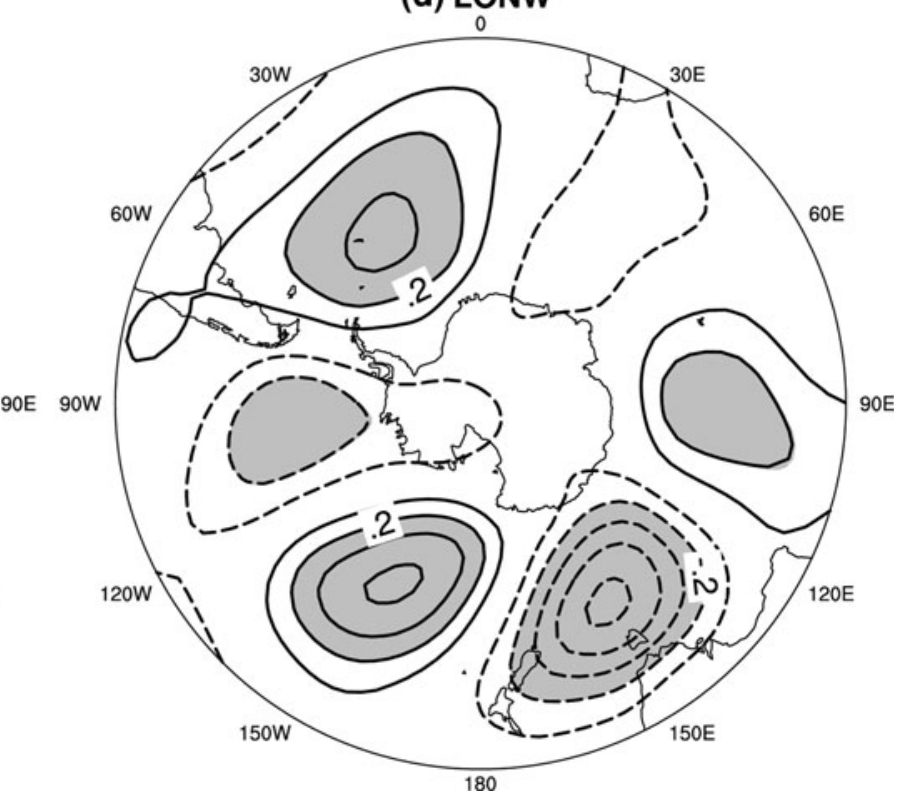

Negative correlations are shown by dashed contours, and statistically significant correlations are shaded gray

ZW3 amplitude was found to have little relationship with the strength of the anticyclones (Fig. 5c), which is surprising given that Fig. $4 \mathrm{~b}$ and $\mathrm{d}$ suggest a relationship between ZW3 and the anticyclone longitudes. A time series of the absolute difference from $120^{\circ}$ of the zonal separation between the anticyclones (i.e. ILONE - LONW - 120l) was negatively correlated with ZW3 amplitude for the winter and late summer seasons, indicating that ZW3 is strongest when the zonal separation between the anticyclones is close to the ZW3 wavelength forced by the 
(a) ZW1 Amplitude

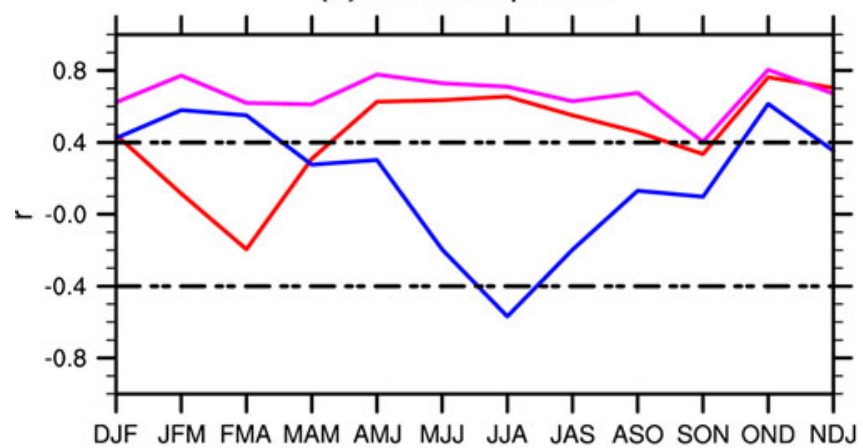

(c) ZW3 Amplitude

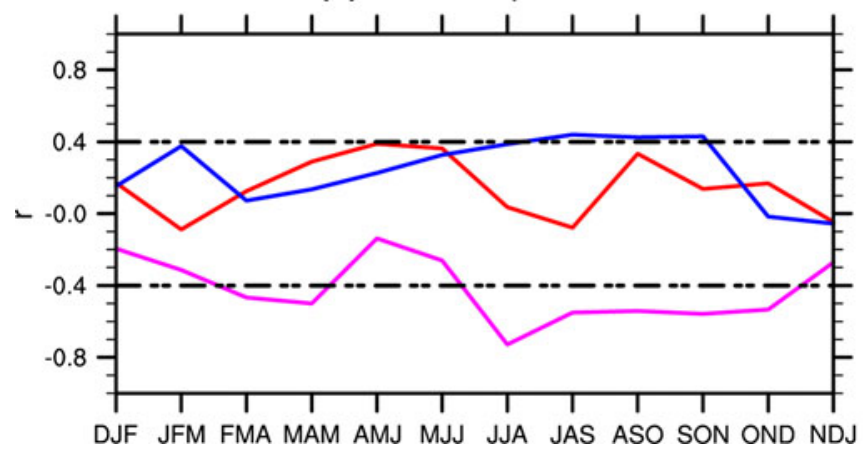

Fig. 5 Correlations between the ZW and quasi-stationary anticyclone time series. a ZW1 amplitude correlation with HGTE (red), HGTW (blue) and maximum of HGTE, HGTW (magenta), b ZW1 phase correlation and LONE (red), LONW (blue) and HGTE-HGTW

Fourier transform. The relationship between ZW3 phase and the anticyclone locations is clearer (Fig. 5d). ZW3 phase is significantly correlated with both the east and west anticyclone longitudes. This shows that the ZW3 pattern moves east-west in approximate phase with the zonal variability of the subpolar anticyclones. Each anticyclone has a roughly similar magnitude of influence on ZW3 phase.

In summary, a large part of the variability expressed by the $\mathrm{ZW} 1$ and $\mathrm{ZW} 3$ patterns appears to be related to the strength and location of the quasi-stationary anticyclones. The relationships between the anticyclones and the zonal waves are somewhat complicated, but at a first pass the ZW1 pattern is related to the combined strength of the two anticyclones, and the ZW3 pattern is related to their longitude.

\subsection{Variance explained by the subpolar anticyclones}

It has been shown that there is a relationship between the SH zonal waves and the quasi-stationary anticyclones, but that the zonal wave patterns mask variance that is independent between the anticyclones. If the anticyclones are to be regarded as useful representation of the $\mathrm{SH}$ atmosphere, (b) ZW1 Phase

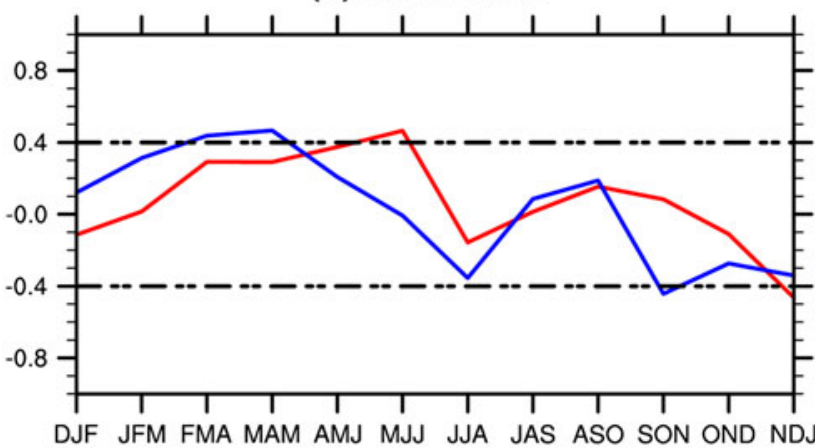

(d) ZW3 Phase

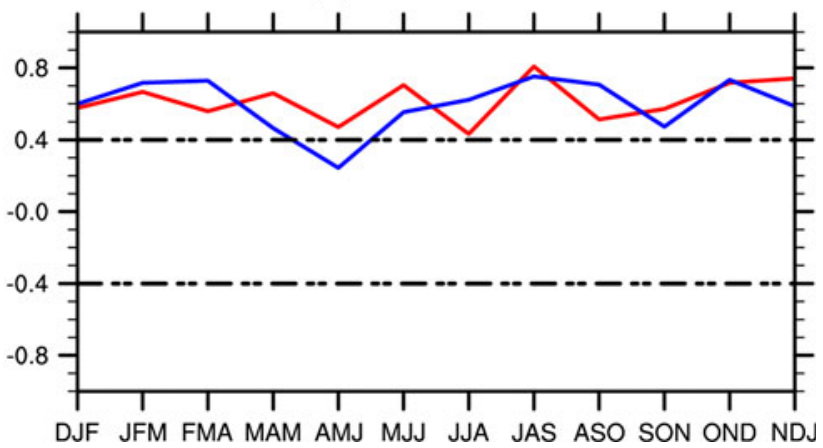

(magenta), c ZW3 amplitude correlation with HGTE (red), HGTW (blue) and ILONE-LONW-120 I (magenta), $\mathbf{d}$ ZW3 phase correlation with LONE (red) and LONW (blue). Horizontal dashed lines indicate correlations significant at the 0.05 level

then clearly they should explain a significant amount of the atmospheric variability. In this section the variance attributable to the anticyclones is estimated.

Consider a time series, $X$, of sample-size $N$. By definition:

$\operatorname{var}(X)=\sum_{i=1}^{N} \frac{\left(X_{i}-\bar{X}\right)^{2}}{N-1}=\sum_{i=1}^{N} \frac{\left(X_{i}^{\prime}\right)^{2}}{N-1}$

where the mean is denoted by an overbar, and an anomaly is denoted by an apostrophe.

Let $X_{i}=$ the linear result of two time series $Y_{i}, Z_{i}$, such that:

$X_{i}=a Y_{i}+b Z_{i}+$ residual $_{i}$

where $a$ and $b$ are constant coefficients.

Substituting the second equation above into the first, and recalling that $\gamma(Y, Z)=\sum_{i=1}^{N} \frac{Y_{i}^{\prime} Z_{i}^{\prime}}{N-1}$, where $\gamma(Y, Z)$ is the covariance between $Y$ and $Z$, gives:

$\operatorname{var}(X)=\operatorname{var}(a Y)+\operatorname{var}(b Z)+\operatorname{var}($ residual $)+2 a b \gamma(Y, Z)$

assuming that since the residual term is non-covariant with $Y$ or $Z, \gamma(Y$, residual $)=\gamma(Z$, residual $)=0$. 
This method was used to estimate the variability of the SH $500 Z$ field explained by the anticyclone time series. If the time series were independent, i.e. $\gamma(Y, Z)=0$ in the above example, then the coefficients could be estimated using the Least-Squares method. However, it has been shown in Sect. 3.2 above that this is not the case, and least-squares multiple regression is an ill-constrained estimator (e.g. von Storch and Zwiers 1999). Instead, simple regression was applied iteratively to each of the time series; having calculated the signal for the first time series, the signal was removed from the data and regression was then performed for the resultant residual and the next time series. Whilst this does not allow a comparison of the individual time series, the total variance explained by the time series combined can be estimated having overcome the covariance problem. Tests have indicated that the solutions are relatively insensitive to the order in which the time series are regressed on the data (differences are less than $5 \%$ of the total variance).

Figure 6 shows the variance explained by the HGTE, HGTW, LONE and LONW time series combined. In the annual mean, the variance explained by the subpolar anticyclones (Fig. 6a) is concentrated in the region of influence of the eastern anticyclone (as shown by Fig. 4a), which suggests that the eastern anticyclone is more important than the western anticyclone at interannual timescales; a similar pattern is apparent for MJJ (Fig. 6c). During the ASO and NDJ periods there is significant link with tropical Pacific variability (Fig. 6d, e), which corresponds to the season of greatest ENSO activity. This indicates that the anticyclone time series are able to capture the ENSO-teleconnection to the high SH that is synonymous with the PSA mode. An important point is that there is little evidence of a zonally complete ZW3 in the variance estimates. Only for the ASO and FMA seasons are the anticyclones linked to variability over the Indian Ocean basin (Fig. 6b, d), whereas the ZW3 pattern would of course include variability in that region during all seasons (as shown by Fig. 1d). Moreover, the regions in the eastern hemisphere linked to the anticyclones are not consistent with centers of action with a zonal separation of $120^{\circ}$, as forced by the Fourier transform; Fig. 1 indicates that those regions are clear only when ZW1 and ZW3 are superposed.

\section{Comparison with the SH climate modes}

Section 3 established that the subpolar Pacific anticyclones represent an important fraction of variability of the $\mathrm{SH}$ mid-troposphere. In this section, the anticyclones are compared with the recognized dominant modes of $\mathrm{SH}$ variability; the SAM and the PSA.

The well-recognized SAM pattern includes a center of action over the Amundsen Sea, implying a covariance between the SAM and the eastern anticyclone (e.g. Thompson and Wallace 2000). The LONE time series is significantly positively correlated with the annual mean SAM index, and for all seasons except NDJ, indicating a tendency for the east anticyclone to be in an eastern location when the SAM is strong. Thompson and Wallace (2000) showed that when the SAM is positive pressure tends to be reduced in the Amundsen/Bellingshausen Sea region, a condition which corresponds to an eastern shift in the east anticyclone (Fig. 4b). By contrast to LONE, the HGTE time series is significantly correlated with the SAM index only for ASO and NDJ. There is a significant correlation in early winter between the SAM index and the LONW ( $r=0.56$ ), but this may partly due to the covariance between LONE and LONW.

The covariance between the SAM and the anticyclone location raises the question of whether the anticyclones, and in particular the east anticyclone, provide additional information regarding variability that is not given by the SAM. Using the variance-partitioning method outlined in Sect. 3.4, the SAM-signal was removed from the $500 \mathrm{hPa}$ geopotential height, and the variance of the SAM-free data explained by the anticyclone time series was estimated (Fig. 7). The variance-explained is reduced compared to Fig. 6, particularly in the region of the Bellingshausen/ Amundsen Seas, where the zonally asymmetric component of the SAM is most prominent, and which is close to to the mean location of the east anticyclone. The greatest reduction in this region is for the annual mean and MJJ (Figs. 6a, c, 7a, c), when most of the variance-explained seems to be due to the east anticyclone. Interestingly, MJJ corresponds to the season when the east anticyclone is furthest west (Fig. 2b), and thus is closest to the Bellingshausen Sea. During other seasons the east anticyclone is further east than the SAM's zonally asymmetric component (e.g. FMA; Fig. 2b), and the reduction in variance due to the SAM is much less (Fig. 6b). Hence, while much of the variance due to the east anticyclone may also be attributed to the SAM, there remains a significant portion of variance explained, especially east of the Bellingshausen Sea. The reduction in variance explained is much less in the region of the Ross Sea, which is a clear indication that the west anticyclone represents variability in the west Antarctic region that is not captured by the SAM.

The $500 \mathrm{Z}$ variance explained by the second and third PCs (i.e. the PSA) is shown on Fig. 8. In general, the PSA time series explain a significant proportion of variability over the central Pacific sector of the Southern Ocean. The largest signal is during ASO (Fig. 8d); we note that the ENSO-teleconnections with the $\mathrm{SH}$ are strongest in spring (Fogt and Bromwich 2006). Further analysis shows a statistically significant correlation between the PC3 and LONE time series for all seasons $(0.6>r>0.4)$, but not for the 

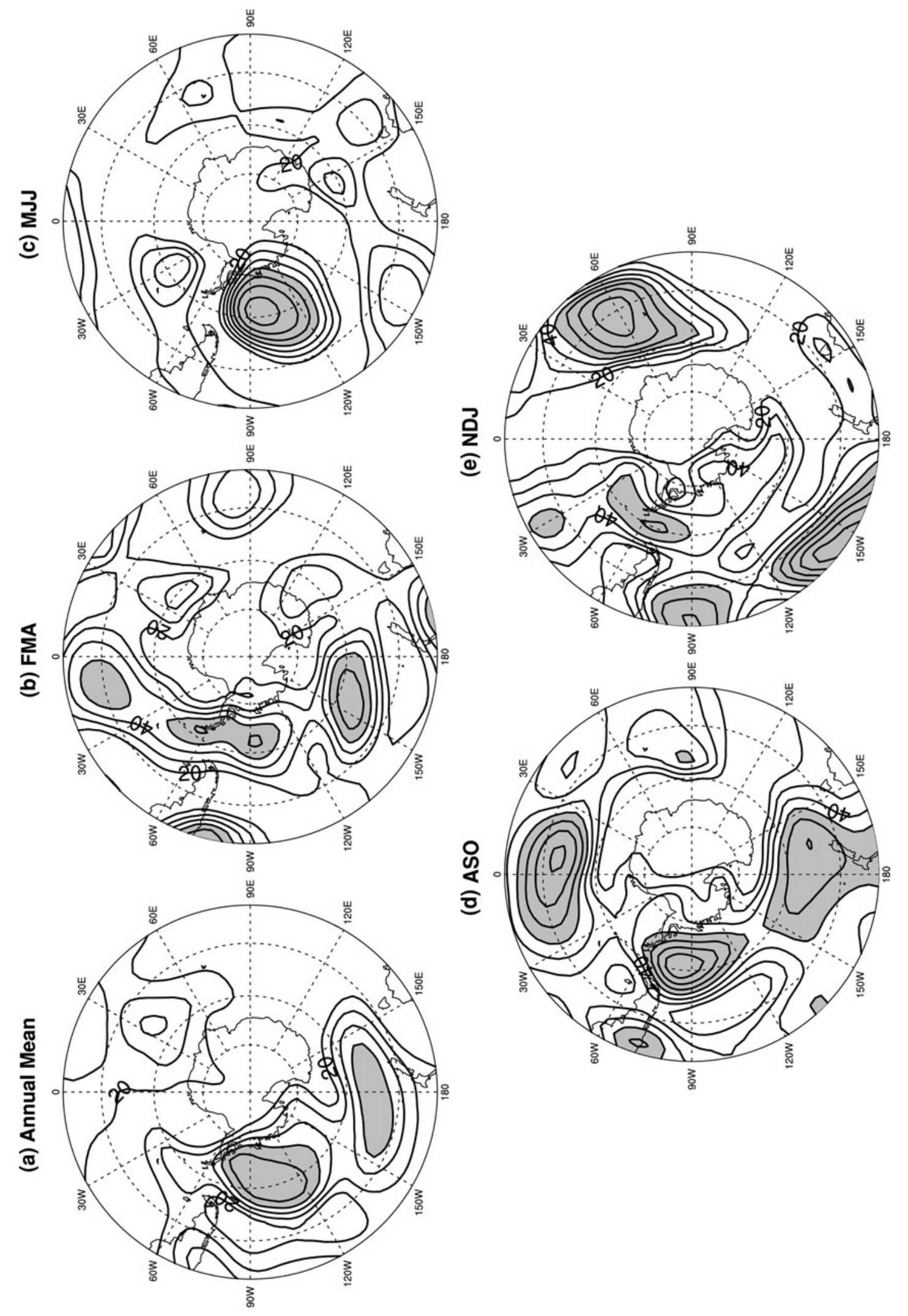

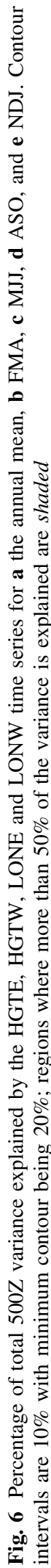



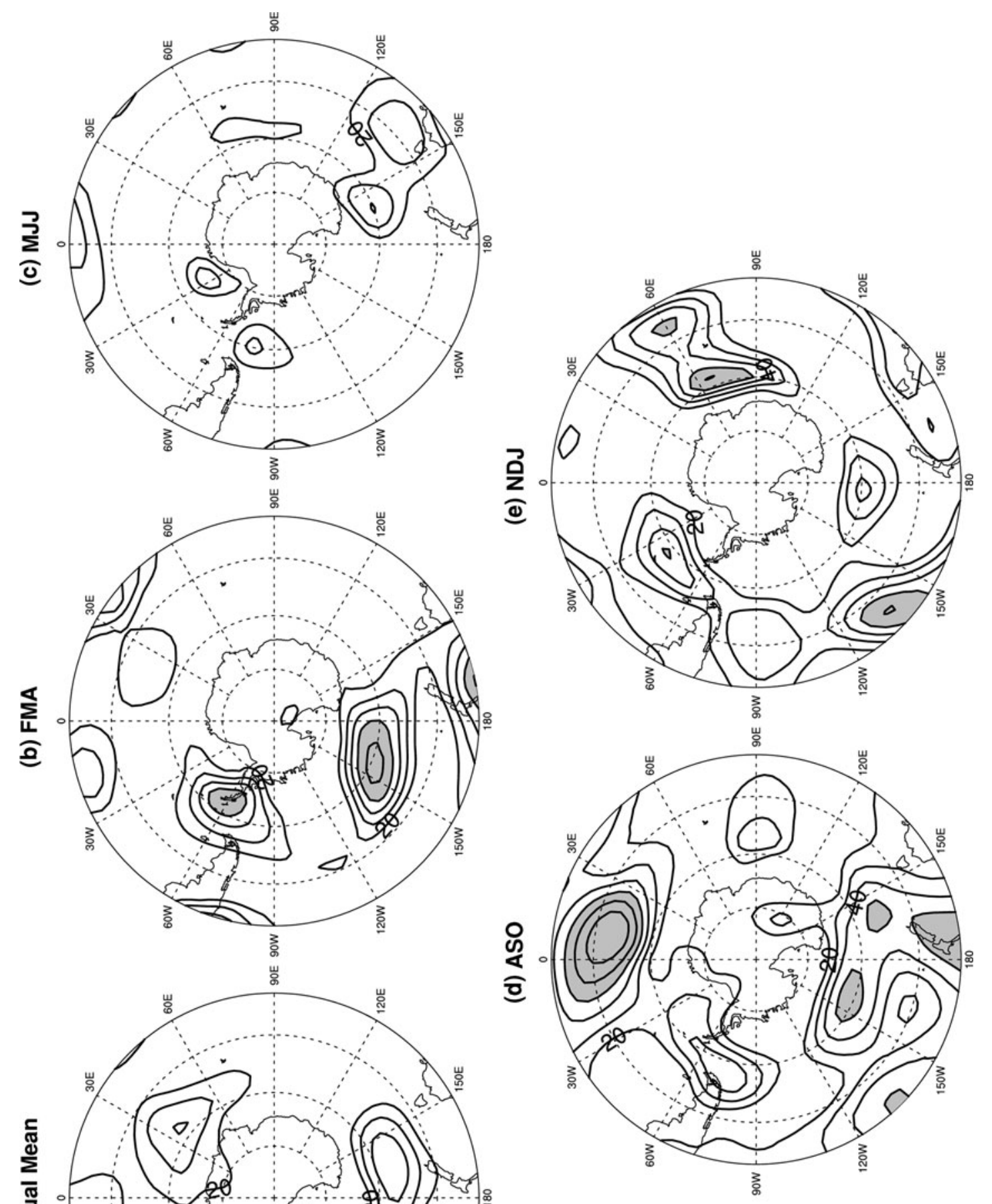

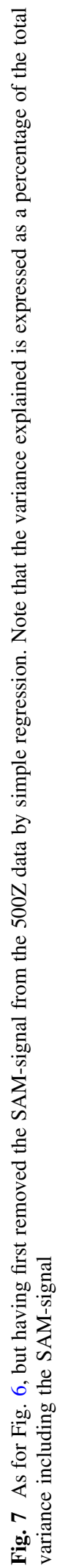



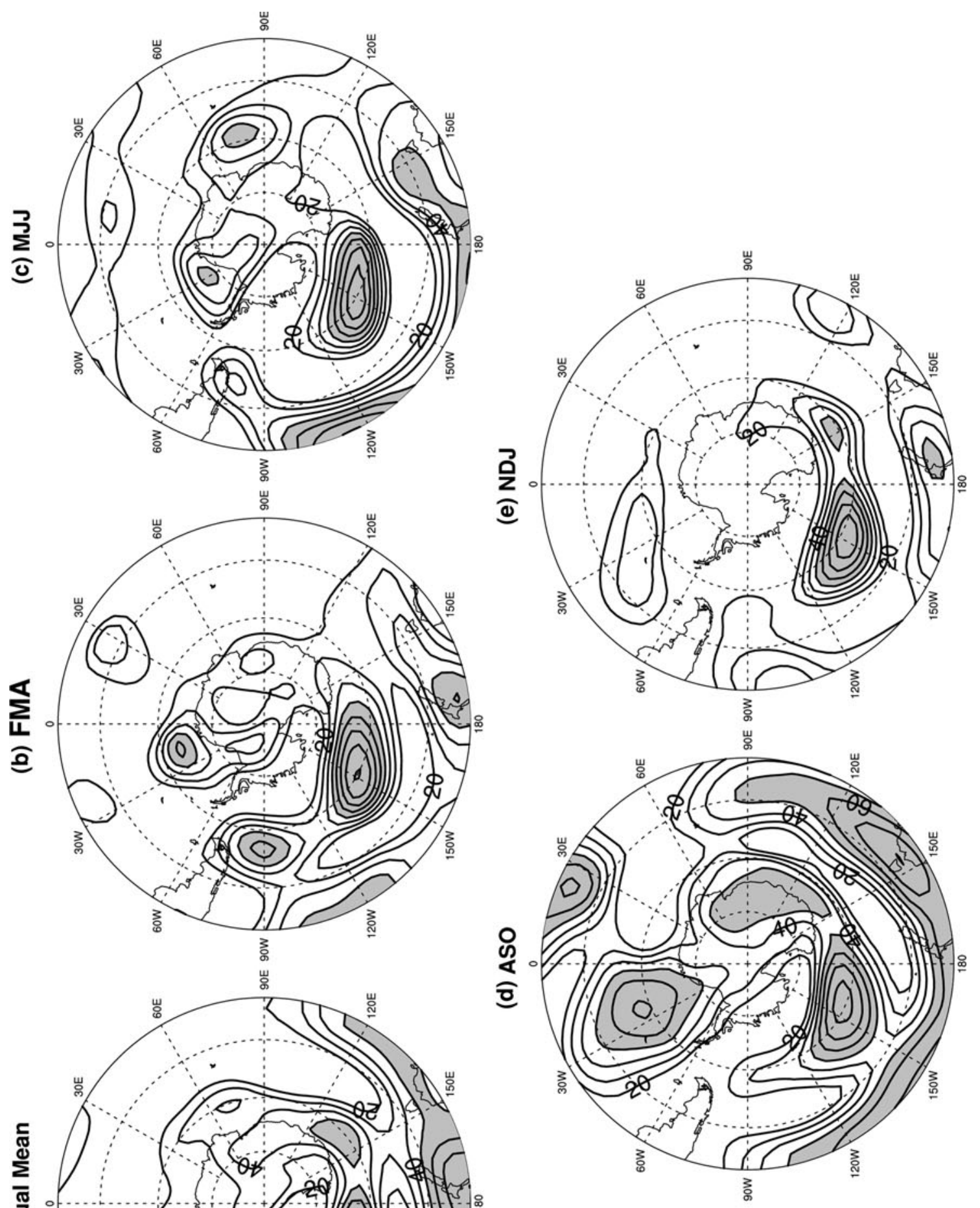

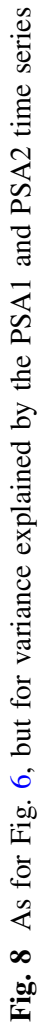


annual mean, whereas PC2 and LONE are only significantly correlated during summer $(r=0.45)$. Additionally, east anticyclone strength (HGTE) is negatively correlated with PC3 for the annual mean and all seasons other than NDJ $(-0.4>r>-0.6)$.

Whilst PC2 seems to have little relation to the east anticyclone, it is significantly correlated with HGTW during the FMA and ASO $(r=0.50)$, and with LONW during ASO and NDJ ( $r=-0.82$ and $r=-0.56$, respectively), indicating that the spring west anticyclone tends to be stronger and further west when PC2 is stronger. The reason for this covariance appears to be the PSA-signal in the region south of New Zealand (approximately 30\% of variance explained, Fig. 8), which is approximately colocated with the west anticyclone (Fig. 4c). The results indicate that the PSA1 mode (i.e. PC2) is related to the west anticyclone, whereas the PSA2 mode (i.e. PC3) is related to the east anticyclone. Thus, a possible physical explanation for the poor separation between the second and third principal components could be that PC2 represents the west anticyclone response to tropical Pacific variability, and the PC3 represents the east anticyclone response.

(a) HGTE

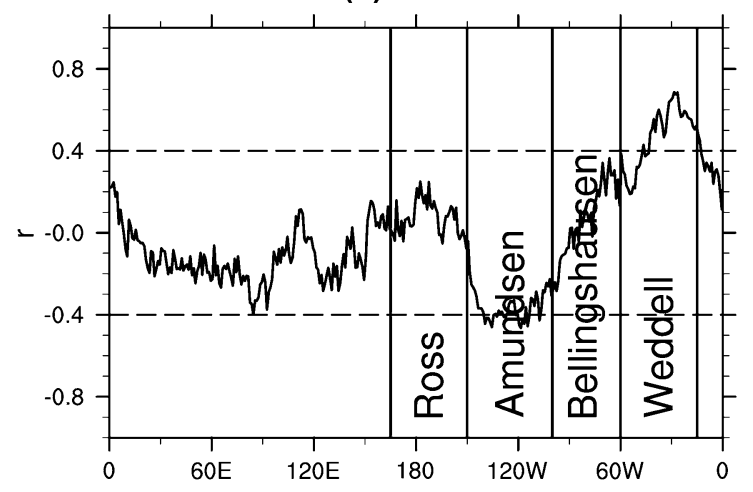

(c) HGTW

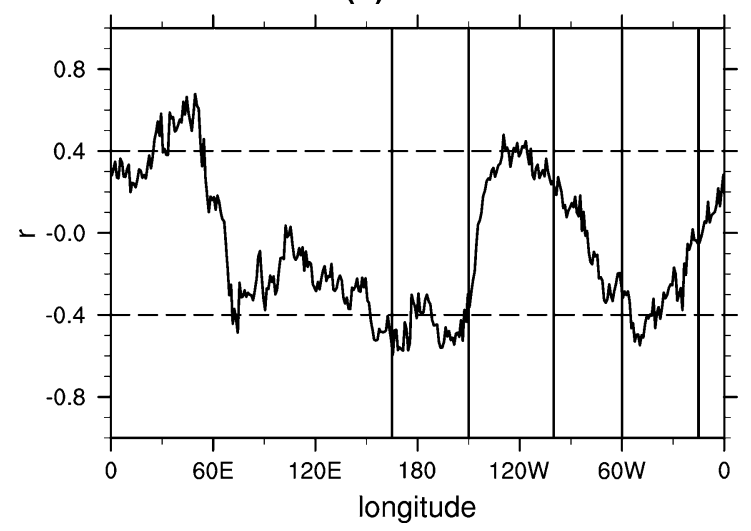

Fig. 9 1979-2007 correlation coefficient at each longitude between ASO sea ice extent and a MJJ HGTE, b MJJ LONE, c ASO HGTW, d ASO LONW. Horizontal dashed lines indicate the correlations that

\section{Discussion and conclusions}

The variability of the SH high latitude troposphere has been analyzed with regard to the zonally asymmetric circulation. Between them, the zonal waves 1 and 3 replicate the long-term mean zonal anomaly remarkably well, consistent with previous studies. However, analysis of individual monthly means suggests that the zonal wave pattern is not as well defined for shorter time scales. The monthto-month pattern of the zonally asymmetric SH troposphere is dominated by two quasi-stationary anticyclones in the western sector of the Southern Ocean. The strength of the anticyclones seems to be related to ZW1, and their longitude seems to be related to $\mathrm{ZW} 3$.

Whilst there is covariance between the locations of the anticyclones, their strengths are negatively correlated, thus they may not be best represented as a zonal wave that gives equal amplitude to both anticyclones. The anticyclones occur in regions where the Antarctic climate system has been shown to respond to meridional airflow. Renwick (2002) showed that the influence of ENSO on Antarctic sea ice extent (SIE) was concentrated around the Drake

(b) LONE

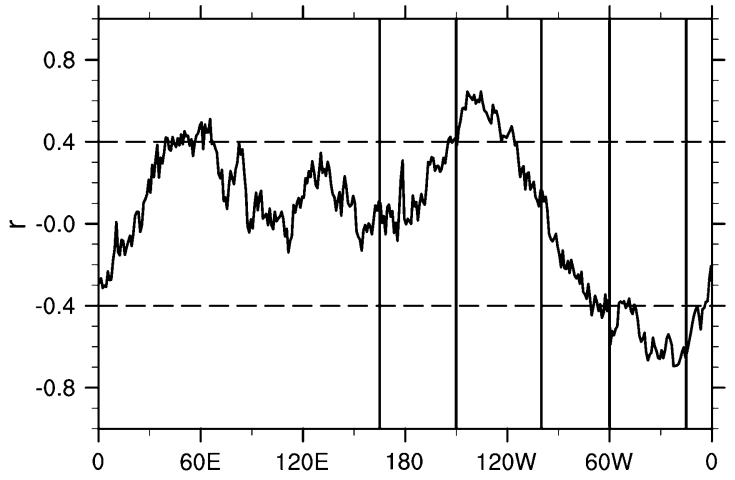

(d) LONW

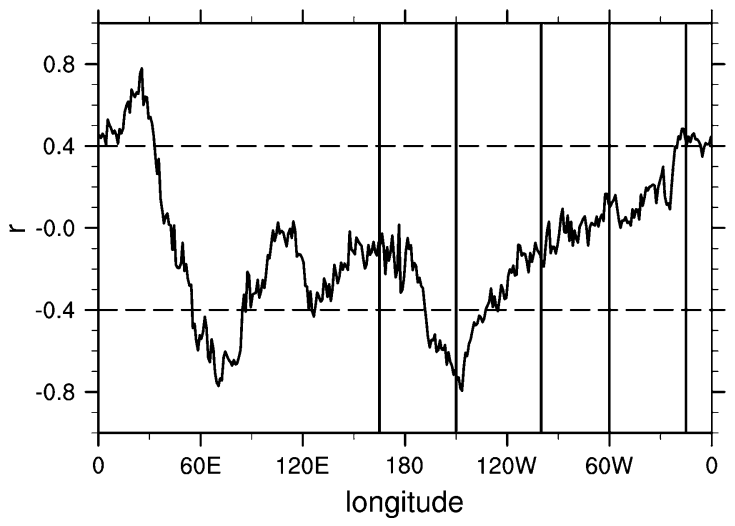

are statistically significant at the 0.05 level. Vertical lines indicate west Antarctic sectors, as named in (a) 
Passage, a region corresponding to the approximate location of the east anticyclone. Furthermore, the atmospheric pattern associated with these sea ice anomalies closely resembles the influence of the east anticyclone strength and longitude shown in Fig. 4a and b. In the region of the west anticyclone, it has been shown that Ross Sea ice response to ENSO events is related to longitudinal shifts in the Amundsen Sea low, and the consequent shift of warm, poleward airflow (Bertler et al. 2004). Figure 9 shows the correlation between the anticyclone time series and the 1979-2007 late winter SIE derived from the HadISST monthly mean ice fraction (where SIE is defined here as the latitude of the $30 \%$ ice fraction isopleth at each longitude). It can be seen that the early winter (MJJ) east anticyclone is associated with sea ice variability in the Weddell Sea (Fig. 9a, b), such that SIE tends to be further north when the east anticyclone is stronger and further west (i.e. low LONE). The east anticyclone longitude is also related to Amundsen Sea ice (Fig. 9b). The west anticyclone is related to SIE variability in the Ross and Amundsen Seas, with the west anticyclone longitude showing the strongest correlations (Fig. 9c, d). Thus, previous research and the initial results in Fig. 9 clearly indicate that atmospheric circulations related to the anticyclones could be a factor in the observed changes in west Antarctica. Detailed analysis of the relationship between the anticyclones and Antarctic sea ice variability is ongoing.

Since these changes are spatially heterogeneous, the use of large-scale patterns such as ZW3 may mask important aspects of local variability. A further advantage of the anticyclones over the ZW decomposition is one of simplicity. Although there are clear links between ZW1 and ZW1 and the anticyclones, the relationship is somewhat complex. Previous research suggests that in the context of Antarctic climate the most important variability is concentrated on the western sector of the Southern Ocean. However, the Fourier transformed zonal waves are obviously influenced by variability throughout the entire latitude, and in this case variance in the Atlantic/Indian sectors may be dynamically unrelated 'noise'.

Comparison with the leading mode of variability, the SAM, shows that while there is some covariance between the SAM and the anticyclones, there remains a significant percentage of variability explained by the anticyclone time series that is unrelated to the SAM. Comparison with the second and third leading modes, the PSA, indicates that the subpolar Pacific anticyclone pattern captures much of the same variability as the PSA. In particular the west anticyclone seems to have some relation to $\mathrm{PC} 2$, and the east anticyclone has a relation with PC3. However, estimates of variance-explained indicate that the subpolar anticyclones explain more of the $500 \mathrm{Z}$ variability than the PSA as represented by PCs 2 and 3 .
Although the work presented here focuses on monthly mean data, the persistent anticyclones in the monthly mean may be linked to blocking events on synoptic timescales. Trenberth and Mo (1985) analyzed SH blocking events lasting 5 days or longer, and found that persistent geopotential height anomalies occurred throughout the year south of New Zealand, in a region corresponding to that of the west anticyclone. A second region was evident in the Drake Passage, corresponding to the east anticyclone location, which was much more significant in winter, consistent with the seasonality of the east and west blocks in Fig. 5. They also found a tertiary preferred blocking location over the Indian Ocean, such that a wavenumber-3 was clear in the blocking regions. Further analysis showed that simultaneous blocking at all three ZW3 peaks was rare, which is consistent with the negative correlation between the strength of the anticyclones, and is further evidence that the Fourier transform ZW3 masks the independence of regional atmospheric anomalies. Renwick (2005) found similar patterns of blocking using the NRA and ERA40 datasets used in this study. Future research will explore in depth the role of transient activity in forcing and modulating the persistent anticyclones in the $\mathrm{SH}$.

The Pacific anticyclone pattern represents an alternative to the zonal waves for analysis of the zonally anomalous circulation that may provide a clearer interpretation and a more faithful representation of month-to-month variability. Future research will consider the influence of the subpolar anticyclones on sea ice, surface temperature and ocean variability in the west Antarctic region. Additionally research will consider the mechanisms that maintain and modulate these persistent features of the SH atmosphere.

Acknowledgments This work has been funded by the NSF grant 0327268. NCEP/NCAR Reanalysis data was provided by the NOAA PSD (http://www.cdc.noaa.gov), and ERA40 reanalysis data was provided by the ECMWF (http://www.ecmwf.int). Data analysis was performed using the NCAR Command Language (NCL). Much of this work was undertaken whilst the authors were visiting the National Center for Atmospheric Research.

Open Access This article is distributed under the terms of the Creative Commons Attribution Noncommercial License which permits any noncommercial use, distribution, and reproduction in any medium, provided the original author(s) and source are credited.

\section{References}

Bertler NAN, Barrett PJ, Mayewski PA, Fogt RL (2004) El Niňo suppresses Antarctic warming. Geophys Res Lett 31:L15208. doi:10.1029/2004GL020749

Fogt RL, Bromwich DH (2006) Decadal variability of the enso teleconnection to the high-latitude South Pacific governed by coupling with the Southern Annular Mode. J Clim 19(6):979997 
Gong D, Wang S (1999) Definition of the Antarctic Oscillation index. Geophys Res Lett 26:1601-1604

Hobbs W, Raphael MN (2007) A representative time-series for the Southern Hemisphere zonal wave One. Geophys Res Lett 34:L05702. doi:10.1029/2006GL028740

Kalnay E et al (1996) The NCEP/NCAR 40-year reanalysis project. Bull Am Meteorol Soc 77:437-471

Karoly DJ (1989) Southern Hemisphere circulation features associated with El Nino-Southern Oscillation events. J Clim 2:1239-1252

Kiladis GN, Mo KC (1998) Interannual and intraseasonal variability in the Southern Hemisphere. In: Karoly DJ, Vincent DG (eds) Meteorology of the Southern Hemisphere. American Meteorological Society, 410

Kwok R, Comiso JC (2002) Spatial patterns of variability in Antarctic surface temperature: connections to the Southern Hemisphere Annular Mode and the Southern Oscillation. Geophys Res Lett 29(14):1705. doi:10.1029/2002GL015415

Lefebvre W, Goosse H (2008) An analysis of the atmospheric processes driving the large-scale winter sea ice variability in the Southern Ocean. J Geophys Res 113:C02004. doi:10.1029/ 2006JC004032

Liu J, Curry JA, Martinson GM (2004) Interpretation of recent Antarctic sea ice variability. Geophys Res Lett 31:L02205

Marshall GJ (2003) Trends in the Southern Annular Mode from observations and reanalyses. J Clim 16:4134-4143

Marshall GJ, Lagun V, Lachlan-Cope TA (2002) Changes in Antarctic Peninsula tropospheric temperatures from 1956 to 1999: a synthesis of observations and reanalysis data. Int $\mathbf{J}$ Climatol 22(3):291-310. doi:10.1002/joc.758

Marshall GJ, Orr A, van Lipzig NPM, King JC (2006) The impact of a changing Southern Hemisphere Annular Mode on Antarctic Peninsula summer temperatures. J Clim 19:5388-5403. doi: $10.1175 / \mathrm{JCLI} 3844.1$

Mo KC, Ghil J (1987) Statistics and dynamics of persistent anomalies. J Atmos Sci 44:877-902

Mo KC, Higgins RW (1997) Planetary waves in the Southern Hemisphere and linkages to the Tropics. Studies in Climate II, Harry van Loon Symposium, Tech. Note NCAR/TN-433+PROC, 90-106

Mo KC, Paegle JN (2001) The Pacific-South American modes and their downstream effects. Int J Climatol 21(10):1211-1229. doi: $10.1002 /$ joc. 685

Monaghan AJ, Bromwich DH, Chapman W, Comiso JC (2008) Recent variability and trends of Antarctic near-surface temperature. J Geophys Res 113:D04105. doi:10.1029/2007JD009094

Quintanar AI, Mechoso CR (1995) Quasi-stationary waves in the Southern Hemisphere, part II: generation mechanisms. J Clim 8:2673-2690
Raphael MN (2004) A zonal wave 3 index for the Southern Hemisphere. Geophys Res Lett 31:L23212

Raphael MN (2007) The influence of atmospheric zonal wave three on Antarctic sea ice variability. J Geophys Res 112:D12112. doi: 10.1029/2006JD007852

Renwick JA (2002) Southern Hemisphere circulation and relations with sea ice and sea surface temperature. J. Climate 15:3058-3068

Renwick JA (2005) Persistent positive anomalies in the Southern Hemisphere circulation. Mon Weather Rev 133:977-988

Steig EJ, Schneider DP, Rutherford SD, Mann ME, Comiso JC, Shindell DT (2009) Warming of the Antarctic ice-sheet surface since the 1957 international geophysical year. Nature 457:459462. doi:10.1038/nature07669

Thomas R et al (2004) Accelerated sea-level rise from West Antarctica. Science 306:255. doi:10.1126/science.1099650

Thompson DWJ, Solomon S (2002) Interpretation of recent Southern Hemisphere climate change. Science 296:895-899

Thompson DWJ, Wallace JM (2000) Annular modes in the extratropical circulation, part I: month-to-month variability. J Clim 13:1018-1036

Thompson DWJ, Wallace JM, Hegerl GC (2000) Annular modes in the extra-tropical circulation, part II: trends. J Clim 13:10181036

Trenberth KE (1980) Planetary waves at $500 \mathrm{hPa}$ in the Southern Hemisphere. Mon Weather Rev 108:1378-1389

Trenberth KE, Mo KC (1985) Blocking in the Southern Hemisphere. Mon Weather Rev 113:3-21

Turner J, TA Lachlan-Cope, S Colwell, GJ. Marshall, WM Connolley (2006) Significant warming of the Antarctic winter troposphere. Science 311:5769, 1914-1917. doi:10.1126/science.1121652

Uppala SM et al (2005) The ERA-40 re-analysis. Q J R Met Soc 131:2961-3012

Van Loon H (1967) The half-yearly oscillation in middle and high southern latitudes and the coreless winter. J Atmos Sci 24:472-486

Van Loon H, Jenne RL (1972) The zonal harmonic standing waves in the Southern Hemisphere. J Geophys Res 77(6):992-1003

Vaughn DG, Marshall GJ, Connolley WM, Parkinson C, Mulvaney R, Hodgson DA, King JC, Pudsey CJ, Turner J (2003) Recent rapid regional climate warming in the Antarctic Peninsula. Clim Chang 60:243-274

von Storch H, Zwiers FW (1999) Statistical analysis in climate research. Cambridge University Press, Cambridge, pp 160-166

Yuan X, Li C (2008) Climate modes in southern high latitudes and their impacts on Antarctic sea ice. J Geophys Res 113:C06S91. doi:10.1029/2006JC004067

Zwiers FW, von Storch H (1995) Taking serial correlation into account in tests of the mean. J Clim 8:336-351 